\title{
Русская автобиографическая проза последних лет в зеркале литературного конкурса «Бунинская премия»
}

\author{
К. Н. КИСЛИЦЫН, А. Б. РОДИН, И. В. КАЗАКОВА \\ (НАЦИОНАЛЬНЫЙ ИССЛЕДОВАТЕЛЬСКИЙ УНИВЕРСИТЕТ «МЭИ», Г. МОСКВА)
}

В статье рассматриваются лучшие автобиографические произведения, выдвигавшиеся на литературный конкурс «Бунинская премия» за последние несколько лет, как часть современного литературного процесса России, а также выявляется их связь с традиционными произведениями русской литературы, написанными в данном жанре.

Теоретическим основанием исследования является современная концепция теории автора, на основании которой была выявлена тенденция к художественному обобщению частных форм жизни в современной российской прозе. Она проявляется в виде автобиографической «чувствительности» у автора, умноженной на широкие социоисторические и художественные обобщения в изображении народного бытия.

В анализируемых текстах традиционные художественные элементы могут органично сочетаться с некоторыми новаторскими приемами и решениями. Так, различные документальные элементы, свидетельствующие о серьезной работе писателя с конкретными фактами, соотнесенные с художественными - вымышленными элементами-деталями, помогают создать иллюзию сопричастности судьбы читателя судьбам главных героев произведения (роман Ю. Полякова «Грибной царь» 2005 г.; «Чеченские рассказы» 2008 г. А. Карасева). Проблема взаимоотношения художественного языка и мышления находит у большинства авторов сложное полифоническое решение в диапазоне от экзистенциализма до постмодернизма (например, сборник «Маленькая девочка из «Метрополя» 2006 г. Л. Петрушевской). Новаторство проявляется также и в авторских экспериментах с жанрами, границы которых искусственно «раздвигаются» (например, «повесть ассоциаций», «роман ассоциаций» Е. Гаммера в сборнике «Один - на все четыре стороны» 2007 г.).

Авторы отмечают ведущую роль сложных полифонических и синтетических приемов и решений, формирующих идейно-нравственную и художественную природу современных прозаических текстов.

Ключевые слова: Бунинская премия; литературный процесс; жанр; культура; русская проза; автобиографизм; интертекстуальность; русская литература

\section{BВЕАЕНИЕ}

Чакануне очередного дня рождения Ивана Алексеевича Бунина (22 октября) хочется вспомнить, а точнее, предаться интертекстуальным размышлениям по мотивам творчества победителей и лауреатов литературного конкурса «Бунинская премия» последних лет. Нужно напомнить, что Бунинская премия - это литературная награда, которая начиная с 2005 г. ежегодно вручается за выдающиеся достижения в области современной русской литературы. Премия посвящена памяти известного русского писателя Ивана Алексеевича Бунина. Председателем Попечительского совета Бунинской премии является ректор Московского гуманитарного университета И. М. Ильинский. Председатель жюри - писатель и литературовед Б. Н. Тарасов.

Вспомним самые интересные произведения, написанные в жанре автобиографической прозы замечательными российскими (проживающими как на террито- 
рии России, так и за ее пределами) прозаиками, публицистами, поэтами, и попытаемся осмыслить как художественное, так и культурное наследие великого русского писателя, а вместе с тем проанализировать духовные, культурные и художественные традиции отечественной литературы, разглядеть вектор ее дальнейшего развития, то, как мысль, воплощенная в слове, отозвалась - отзывается сегодня в «сухом» и не вполне художественном термине «литературный процесс».

Отмечая важную взаимосвязь между явлениями литературной премии и литературного процесса как структурообразующими әлементами развития художественно-эстетического и культурного процесса, а значит, и мышления человека в современном обществе, известные литературоведы и культурологи С. Бэлза, Ю. $\Lambda$. Воротников и Вл. А. Ауков пишут: «...в XIX в., например, литературных премий фактически не было, это не было формой влияния на литературу, на писательское сообщество. Ни в XVII, ни в XVIII в. никто не поступал таким образом. Это некий новый признак XX в., а уж XXI и подавно, когда премия становится очень важным, значительным фактором развития литературного процесса. Без премии, пожалуй, уже нельзя в нем сориентироваться, так как увеличивается количество публикаций, увеличивается количество грамотных людей» (Бэлза, Воротников, Ауков, 2009: 28). Таким образом, литературная премия является на сегодняшний день неким важным ориентиром-мерилом формирования не только хорошего художественного вкуса, но и морально-этических основ воспитания человека-читателя. «В этом смысле главной заслугой и удачей Бунинской премии можно считать попытку найти величину постоянную, выступить связующим звеном российского художественного «диалектического единства» в ситуации той культурной дезориентации и разобщенности, когда старые связи уже утрачены, а новые еще не успели образоваться» (Кислицын, 2010: 114).

В настоящей статье рассмотрены некоторые идейно-художественные и культурные особенности русской автобиографической прозы последних лет в зеркале литературного конкурса «Бунинская премия» и в контексте современного литературного процесса.

\section{ОСОБЕННОСТИ НАПИСАНИЯ АИТЕРАТУРНОЙ АВТОБИОГРАФИИ}

В современном литературоведении понятие «автобиографизм» до сих пор не имеет определенных границ. Одни критики и литературоведы понимают под этим термином литературу документальную, другие - исповедальную, но те и другие сходятся в одном мнении - что в основе литературы биографической лежат факты из личной жизни писателя, необходимые ему для выстраивания сюжета и раскрытия характеров персонажей. В этом смысле проза Юрия Полякова несомненно автобиографична (т. е. в ней присутствует и документальность, и исповедальность одновременно), независимо от того, например, установят или не установят его будущие биографы какие-то параллели между образом автора-повествователя из романа «Козленок в молоке» (1995) и лицом реального писателя. Нельзя однозначно сказать, что понятие «литературный автобиографизм» охватывает только личную сферу жизни писателя, без выхода в пространство народного бытия. Зато не вызывает сомнений тот факт, что такие произведения Ю. Полякова, как семейная сага-трилогия «Замыслил я побег» (1999), «Грибной царь» (2005), роман «Козленок в молоке» (1995), повесть «Апофегей» (1990), несут в себе безусловные 
признаки прозы автобиографической, «ценностный центр» которой, по определению М. Бахтина, составляют «социальные и прежде всего семейные ценности... организующие частную форму жизни» (Бахтин, 1979: 58). С этой точки зрения Ю. Поляков является одним из ярких писателей-современников, продолжающих бунинскую традицию.

В своей вступительной статье «Как я писал “Апофегей” к одноименной повести сам автор остроумно высказался: «Обычно спрашивают, насколько мои книги автобиографичны. Конечно, они автобиографичны, но не настолько, чтобы наскучить читателям» (Поляков, 1995: 3). Если опираться на теорию автора, выдвинутую А. Ю. Большаковой, то можно прийти к выводу, что в прозе Полякова навстречу друг другу стремятся два автора: автор как биографическая личность и автор как субъект зримого или незримого участника произведения (Большакова, 1999: Электронный ресурс). Хотя, безусловно, биографический и «литературный»автор по определению не могут совпасть, как бы они к тому ни стремились. И конечно, в «Грибном царе» главный герой - не сам Поляков. Однако личные переживания последнего по поводу того, что случилось с русским человеком и страной на излете ХХ в., и определяют духовно-художественный мир этого произведения «из истории одной (пост)советской семьи». Точно так же обстоит дело и с романами «Козленок в молоке» и «Замыслил я побег». Как неоднократно отмечал сам автор в различных интервью, в них через изображение локальной ситуации передается мироощущение человека (пост)советской цивилизации.

Тенденция к художественному обобщению частных форм жизни проявилась у писателя задолго до написания «Грибного царя» - еще в его ранних произведениях. Впечатления от службы в армии отражены в запрещенной цензурой в 1980-х годах повести «Сто дней до приказа» (опубликована в 1987 г.), опыт работы в райкоме комсомола - в вызвавшей широкую дискуссию повести «ЧП районного масштаба» (опубликована в 1985 г.), опыт школьного учителя отражен в «Работе над ошибками» (1986). Резкое неприятие событий 1991 г. и их последствий нашло воплощение в произведениях о (пост)советской России - «Аемгородок» (1994), «Небо падших» (1997) и др.

В прозе Полякова всегда было ярко выражено лирическое начало, что во многом и определило его популярность в широких читательских кругах. В этом отношении российского писателя можно считать продолжателем исповедальной традиции русской литературы - от Аввакума до В. Астафьева. Именно этот «мужской лиризм», если так можно выразиться, автобиографическая «чувствительность», умноженная на широкие социоисторические и художественные обобщения в изображении народного бытия, и роднит произведения современного писателя с лучшими образцами русской биографической прозы.

Сборник повестей, рассказов и эссе «Маленькая девочка из "Метрополя"» (2006) Июдмилы Петрушевской также продолжает традицию русской классической литературы и позы. С точки зрения композиции книга имеет четко выстроенную структуру - в главах описывается жизнь героини по мере ее взросления от первых, в семилетнем возрасте, литературных выступлений, от забавных школьных и университетских историй до работы на радио, первых пьес и подпольных спектаклей. В книге удивительно тонко выдержан баланс между фактографичностью и художественностью (Петрушевская, 2006). При этом сборник имеет очень 
сложную внутреннюю архитектонику. В повести, которая и дала название всей книге, автор, заявляя о своих генетических корнях, рассказывает о своем деде Николае Яковлеве, который считается составителем около 70 алфавитов. В последнем рассказе «О "Николаице" $\Lambda$. Петрушевская предлагает вариант собственного алфавита. В ритмике двух принципиальных вопросов современной культуры как найти язык, способный отразить нынешнюю реальность, и где граница между реальностью и текстом - развивается все творчество $\Lambda$. Петрушевской. В сборнике прозы автор показывает варианты собственного, полифонического решения этих вопросов, дает ответы в диапазоне от экзистенциализма до постмодернизма.

С этой точки зрения автобиография $\Lambda$. Петрушевской становится хронологией внутренних, интимных отношений автора и различного типа текстов: от собственных до классики. Авижение внутрь интертесктуальной вселенной происходит в книге согласно духовной истории российского общества в последние несколько десятилетий, и изменение мироощущения можно как раз выразить в формуле «от әкзистенциализма к постмодернизму».

Прозу Петрушевской отличают легкость стиля, целостность художественных образов, точное изображение характеров. В ней каким-то удивительным образом соседствуют и уживаются занятность и трагичность, внешняя простота разговоров, казалось бы, ни о чем и внутренняя целостность. Именно из этих обрывчатых, обыкновенных историй, как из размытой палитры художника-имажиниста, рождаются запоминающиеся образы, исподволь раскрывающие лейтмотивом проходящую основную тему книги - проблему взаимоотношения художественного языка и мышления. Различные истории, казалось бы, лишь отдаленно связанные с судьбой автора, вдруг неожиданно становятся частью лирико-интимной исповеди героини, соединяя чужие судьбы с ее собственной судьбой в едином и бесконечном интертекстуальном пространстве. В своей книге у автора получилось точно, если не сказать ювелирно, соотнести разные элементы автобиографичности, что подразумевает работу с конкретными фактами, и высоту художественного обобщения.

В произведениях Гаммера, представленных в сборнике «Один - на все четыре родины» (2007), передается дух сразу нескольких периодов развития советской действительности. Читатель видит эволюцию сознания человека от времени Великой Отечественной войны до момента его прощания с Россией-матерью - Родиной. Можно понять, как менялась ментальность многих наших соотечественников (определение вне национальной характеристики), когда гордость за страну сменялась желанием из нее уехать. Трагедия диссидента, по мнению автора, заключается в том, что он не смог жить в своей земле и вынужден умереть на чужбине. Гаммер, хотя номинально и нашел свою родину, уехав в Израиль, остался там один. Именно тема экзистенциального одиночества в современном мире становится стержневой в книге «Один - на все четыре родины».

Книга Ефима Гаммера «Один - на все четыре родины» состоит из нескольких разножанровых произведений: романа, повестей и нескольких рассказов, сопровождаемых авторскими подзаголовками - жанровыми изысками. Повесть «Крапивное семя» (вошедшая в вышеуказанный сборник) - это не что иное, в авторской интерпретации, как «повесть ассоциаций», роман «Один - на все четыре родины» (также из сборника) - это «роман ассоциаций», встречается еще «повесть 
Аля непосвященных» и цикл рассказов с авторским жанровым обозначением «смех нашей боли» (Гаммер, 2007). Правда, авторские изыскания писателя на этом сразу и заканчиваются. И вниманию читателя предстают традиционные повести и рассказы. Вместе с тем именно эта, в хорошем смысле данного слова, жанровая простота и придает прозе Е. Гаммера значимость, делает ее настоящей, честной. А то, что было заявлено в подзаголовках - ассоциативность, - проявляется не в понимании прямых аллюзий на советскую действительность, а в явно просматриваемых традициях русской классической литературы в текстах еврейского автора, который, выдвигая свою национальную суть на первый план, в силу своего таланта не смог уйти от интернационального, правильнее - общечеловеческого, понимания трагедии неоформленности бытия творческой личности в советскую эпоху. Поэтому архетипическая идея «вечного жида», заявленная в заголовке книги, видится скорее политическим шагом в сторону издателей, чем собственно мировоззренческой константой Е. Гаммера.

«Чеченские рассказы» Александра Карасева (2008) - одно из первых художественных свидетельств Чеченской войны. Ао этого по данной теме было написано много произведений публицистического, документального и исторического характера, но чтобы художественных, так сразу и не вспомнить. Правдивые, мощные, наполненные житейской мудростью и юмором, с одной стороны, они продолжают классическую традицию русской «военной прозы», а с другой стороны, это проза о человеке - его мысли, чувства, воспоминания о гражданской жизни, существующей, согласно внутреннему ощущению, где-то совсем рядом и одновременно бесконечно далеко - в параллельной реальности. Мир на войне, а вместе с ним и душа человека-солдата кажутся вывернутыми наизнанку, а реальность человеческих поступков и событий как будто отражается в кривом зеркале: «Армия - порождение и отражение мира гражданского. Но отражение в кривом зеркале. Отражение искажает и преувеличивает, выворачивает наизнанку и превращает в пошлость привычные для человека представления о том, что хорошо, а что плохо, о мере дозволенности, культуре, морали и чести, о дружбе и о войне» (Карасев, 2008: 37).

Вот что пишет о сборнике рассказов Карасева литературный критик А. Рудалев: «Автор каждый раз заново, каждым рассказом погружает читателя в ситуацию войны. Но сам рассказчик при этом отстранен, смотрит со стороны. В технике письма Александр Карасев тяготеет к импрессионистичности. Он не вязнет в деталях и подробностях. Его война чеканится емкой и отточенной, будто штык фразой. Бежать за сюжетом его рассказов - пустое дело, весь их смысл таится в конкретной фразе, в каждой из них - мысль, анализ обретенного опыта, становящийся житейской мудростью» (Рудалев, 2009: Электронный ресурс). Но, несмотря на эту отстраненность, на всю блестящую операторскую работу, читатель понимает, что рассказчик - это сам автор, который не опускается до эгоистично-экзистенциального «я», только - «мы», потому что считает своим долгом показать свою духовную и гражданскую причастность к происходящему, и эта особенность делает его прозу еще более честной, доверительной, открытой, вызывающей чувство сопричастности у читателя: «Теперь, под нещадным кавказским солнцем, мы целыми днями роем окопы и ходы сообщения, сооружаем дзоты и строим блиндаж, валим деревья и устраиваем завалы. Каждый из нас по полночи стоит на по- 
сту, на своей позиции, а с утра принимается за дело. Мы радуемся дождю, прерывающему наш каторжный труд, но мутная вода заполняет окопы, и глиняные их стенки рушатся, погребая нашу работу. Мы падаем от усталости и ночью из последних сил боремся со сном. Мы понимаем, что нас горстка в лесу, что вырезать спящих боевикам не составит труда. Но сон одолевает, он сильнее. Сильнее желания жить» (Карасев, 2008: 42). Таким образом, последняя фраза неожиданно разрастается до пастернаковской «жизнь прожить - не поле перейти» и наполняет ее новыми, доселе неведомыми для русского культурного сознания смыслами.

\section{ЗАКАЮЧЕНИЕ}

Подводя итоги, отметим, что литературная автобиография представляет собой сложное социокультурное и художественное явление, отражающее в себе жизнь целого народа (той или иной социальной его прослойки) за определенный период времени (исторической или культурной эпохи), преломленную в ракурсе личностно-художественного восприятия действительности сочинителем - главным героем.

\section{СПИСОК АИТЕРАТУРЫ}

Бахтин, М. М. (1979) Эстетика словесного творчества. М. : Искусство. 424 с.

Большакова, А. Ю. (1999) Теория автора у М. М. Бахтина и В. В. Виноградова (на материале русской «деревенской прозы») [Электронный ресурс]// Аиалог. Карнавал. Хронотоп. № 2. URL: http://nevmenandr.net/dkx/?y=1999\&n=2\&abs=BOLSH (дата обращения: 05.06.2016).

Бэлза, С. И., Воротников, Ю.,., Ауков, Вл. А. (2009) Мост к классике: Перед вручением Бунинской премии 2008 года // Знание. Понимание. Умение. № 1. С. 26-30.

Гаммер Е. А. (2007) Один - на все четыре родины. Иерусалим - Москва : Издательское содружество А. Богатых и Э. Ракитской. 448 с.

Карасев, А. В. (2008) Чеченские рассказы. М. : Аитературная Россия. 320 с.

Кислицын, К. Н. (2010) Художественная публицистика в зеркале Бунинской премии 2009 г. // Знание. Понимание. Умение. № 1. С. 113-116.

Петрушевская А. С. (2006) Маленькая девочка из «Метрополя». СПб. : Амфора. 75 с.

Поляков, Ю. М. (1995) Апофегей. М. : Русская книга. 160 с.

Рудалев, А. Г. (2009) Книга Александра Карасева «Чеченские рассказы» [Электронный ресурс]// Альманах «Искусство войны». Война от первого лица. URL: http://navoine. info/chechenskiye-rasskazy.html (дата обращения: 05.06.2016).

Аата поступления: 30.06.2016 г.

\section{RUSSIAN AUTOBIOGRAPHICAL PROSE OF RECENT YEARS \\ IN THE MIRROR OF THE BUNIN PRIZE \\ K. N. KISLITSYN, A. B. RODIN, I. V. KaZAKOVA \\ (NATIONAL RESEARCH UNIVERSITY «MPEI», MOSCOW)}

The article examines the most significant autobiographical works nominated for the Bunin Prize in literature over the last few years as part of the contemporary literary process in Russia. We trace their historical links with classical works of Russian literature written in this genre.

Our study makes use of the contemporary theory of authorship which allows us to conceptualize the tendency of generalizing particular forms of life in contemporary Russian prose. This 
trend manifests itself in the 'sensitivity' of the autobiographical author augmented by broad sociohistorical and artistic generalization in depicting of national life.

Autobiographical texts may feature traditional artistic elements in combination with innovative techniques and solutions. In this way, documentary elements based on hard factual research are blended with fictional details in order to create an illusion of belonging in the intertextual space of Yuri Polyakov's novel «The Mushroom Tsar» (2005) and A. Karasev's «Chechen stories» (2008). The problem of the relationship between language of fiction and thought gives rise to two fundamental problems - how to find a language capable of reflecting the current reality, and where the boundary between reality and the text lies. Most contemporary authors present a complex polyphonic solution ranging from existentialism to postmodernism (e.g., L. Petrushevskaya in her collection of prose «The Little Girl from the «Metropol», 2006). The innovation of autobiographical texts can be clearly seen in experiments with genres when authors try to extend their boundaries (e.g. the novella (or novel) "of associations» in E. Gammer's collection of short stories «Alone - to wherever you may head», 2007).

The authors emphasize the leading role of complex polyphonic and synthetic techniques and solutions which shape ideological, moral and artistic nature of contemporary prose.

Keywords: Bunin Prize; literary process; genre; culture; Russian prose; autobiographism; intertextuality; Russian literature

\section{REFERENCES}

Bakhtin, M. M. (1979) Estetika slovesnogo tvorchestva. Moscow, Iskusstvo. 424 p. (In Russ.).

Bol'shakova, A. Yu. (1999) Teoriia avtora u M. M. Bakhtina i V. V. Vinogradova (na materiale russkoi «derevenskoi prozy»). Dialog. Karnaval. Khronotop, no. 2 [online] Available at: http://nevmenandr.net/dkx/?y=1999\&n=2\&abs=BOLSH (access date: 05.06.2016). (In Russ.).

Belza, S. I., Vorotnikov, Iu., L. and Lukov, Vl. A. (2009) Most k klassike: Pered vrucheniem Buninskoi premii 2008 goda. Znanie. Ponimanie. Umenie, no. 1, pp. 26-30. (In Russ.).

Gammer E. A. (2007) Odin - na vse chetyre rodiny. Jerusalem, Moscow, Izdatel'skoe sodruzhestvo A. Bogatykh i E. Rakitskoi. 448 p. (In Russ.). Russ.).

Karasev, A. V. (2008) Chechenskie rasskazy. Moscow, Literaturnaia Rossiia. 320 p. (In

Kislitsyn, K. N. (2010) Khudozhestvennaia publitsistika v zerkale Buninskoi premii 2009 g. Znanie. Ponimanie. Umenie, no. 1, pp. 113-116. (In Russ.).

Petrushevskaia L. S. (2006) Malen'kaia devochka iz «Metropolia». St. Petersburg, Amfora. 75 s. (In Russ.).

Poliakov, Iu. M. (1995) Apofegei. Moscow, Russkaia kniga. 160 p. (In Russ.).

Rudalev, A. G. (2009) Kniga Aleksandra Karaseva «Chechenskie rasskazy». Al'manakh «Iskusstvo voiny». Voina ot pervogo litsa [online] Available at: http://navoine.info/chechenskiye-rasskazy.html (access date: 05.06.2016).

Submission date: 30.06.2016.

Кислицын Константин Николаевич — кандидат филологических наук, доцент кафедры рекламы, связей с общественностью и лингвистики Гуманитарно-прикладного института Национального исследовательского университета «МЭИ». Адрес: 111250, Россия, г. Москва, ул. Красноказарменная, А. 13М. Тел.: +7 (495) 362-71-85. Эл. адрес: kislitsynkn@mpei.ru. SPIN-код РИНЦ: 6532-9437.

Родин Алексей Борисович - директор Гуманитарно-прикладного института Национального исследовательского университета «МЭИ». Адрес: 111250, Россия, г. Москва, ул. Красноказарменная, д. 13М. Тел.: +7 (495) 362-71-85. Эл. адрес: lingva@list.ru 
Казакова Ирина Владимировна - доцент, заведующая кафедрой иностранных языков Гуманитарно-прикладного института Национального исследовательского университета «МЭИ». Адрес: 111250, Россия, г. Москва, ул. Красноказарменная, д. 13М. Тел.: +7 (495) 362-71-85. Эл. адреc: lingva@list.ru

Kislitsyn Konstantin Nikolaevich, Candidate of Philology, Associate Professor, Department of Advertising, PR and Linguistics, Institute of the Humanities and Applied Sciences, National Research University "MPEI". Postal address: 13M Krasnokazarmennaya St., Moscow, Russia Federation, 111250. Tel.: +7 (495)362-71-85. E-mail: kislitsynkn@mpei.ru

Rodin Alexey Borisovich, Director, Institute of the Humanities and Applied Sciences, National Research University "MPEI”. Postal address: 13M Krasnokazarmennaya St., Moscow, Russia Federation, 111250. Tel.: +7 (495) 362-71-85. E-mail: lingva@list.ru

Kazakova Irina Vladimirovna, Associate Professor and Chair, Department of Foreign Languages, Institute of the Humanities and Applied Sciences, National Research University "MPEI". Postal address: 13M Krasnokazarmennaya St., Moscow, Russia Federation, 111250. Tel.: +7 (495) 362-71-85. E-mail: lingva@list.ru 